\title{
Disruptions of the Academic Math Employment Market
}

Amy Cohen

\author{
Communicated by Steven J. Miller
}

Note: The opinions expressed here are not necessarily those of Notices. Responses on the Notices webpage are invited.

The employment structure for $\mathrm{PhD}$ mathematicians is undergoing challenging changes, as reported by the Joint Data Committee over the last few years. This article addresses two of these challenges in light of results from the AMS annual survey [1] and from the Conference Board of the Mathematical Sciences [2].

(1) More Postdocs and Fewer Jobs. The number of postdocs in mathematics is increasing while the number of academic jobs potentially leading to tenure in doctoral departments of mathematics is stagnating. Therefore, research-focused departments should educate graduate students and postdoctoral fellows for a wider range of career opportunities and responsibilities. Departments with postdocs should record where postdocs find their next-and, if possible, subsequent-employment.

Table 1. Recruitment and Hiring 2013-14 to Start Fall 2014 [1 a]

\begin{tabular}{|c|c|c|c|}
\hline \multirow{2}{*}{\multicolumn{2}{|c|}{$\begin{array}{c}\text { Doctoral Math Departments Only } \\
\text { Tenure-Track }\end{array}$}} & \multicolumn{2}{|c|}{ All Math Departments } \\
\hline & & \multicolumn{2}{|c|}{ Tenure-Track } \\
\hline Vacancies posted & Positions filled & Vacancies posted & Positions filled \\
\hline 315 & 265 & 885 & 740 \\
\hline \multicolumn{2}{|c|}{ Full-Time Non-tenure-track* } & \multicolumn{2}{|c|}{ Full-Time Non-tenure-track* } \\
\hline Vacancies posted & Positions filled & Vacancies posted & Positions filled \\
\hline 485 & 485 & 856 & 811 \\
\hline
\end{tabular}

At most 265 of those 400 or 450 postdocs got tenure-track jobs in doctoral departments in 2014. Table 1 indicates that fewer did, since some of those tenure-track postings were for department chairs or for distinguished professorships, jobs that rarely go to early-career mathematicians. Some took jobs in Masters or Bachelors departments with high research expectations.

New PhDs are increasingly taking first jobs outside academia (see Table 2). It is reasonable to conjecture that a similar pattern may obtain for postdocs.
Amy Cohen retired as professor of mathematics at Rutgers Uni-

The author gratefully acknowledges astute comments and suggestions from the referees and editors. They helped to improve earlier versions of this article.

For permission to reprint this article, please contact:

reprint-permission@ams.org.

DOI: http://dx.doi.org/10.1090/noti1423 versity in 2015. Her e-mail address is acc@math. rutgers . edu.

(2) Recent Hiring Off Tenure Track. Over half of recent hiring of full-time $\mathrm{PhD}$ mathematicians by all universities and 4-year colleges has been off the mathematical community should discuss the roles of $\mathrm{PhDs}$ in full-time non-tenure-track positions. In particular, discuss, committee from the AMS and the MAA should Details will surely vary across various sectors of higher education. Broad awareness of the issues by employers and by job seekers will be at least as important as details

\section{Data and Discussion Related to (1)} doc. The main logical possibilities are tenure-track faculty jobs, further postdocs, full-time non-tenure-track faculty jobs, and nonacademic jobs. We are left to make estimates. Assuming 4 percent growth per year, the reported 491 new postdocs in 2013 implies about 450 in 2011, finishing in 2014. Alternatively, dividing the Data Committee's total of 1,398 in 2013 by an average 3-year length (or a bit more than 3 to account for 4 percent growth) also yields about 450 , with about 400 in doctoral departments.

There is currently no systematic tracking of what jobs .

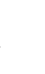
. 
Table 2. Nonacademic employment of new math PhDs reported by survey year [1d]. The table omits PhDs in applied mathematics, statistics, and biostatistics. It also omits those whose status is "not seeking," "still seeking," or "unknown."

\begin{tabular}{|c|c|c|c|c|}
\hline \multirow{2}{*}{\multicolumn{5}{|c|}{$\begin{array}{l}\text { Year of survey (at right) } \\
\text { Type of nonacademic employer (below) }\end{array}$}} \\
\hline & & & & \\
\hline Research institutes \& not-for-profit organizations (US) & 23 & 33 & 26 & 31 \\
\hline Government agencies (US) & 48 & 32 & 48 & 39 \\
\hline Business \& industry (US) & 98 & 160 & 174 & 184 \\
\hline Non-US nonacademic & 14 & 7 & 17 & 15 \\
\hline TOTALS & 183 & 232 & 265 & 269 \\
\hline Percentage of all PhDs granted by math departments & $16 \%$ & $20 \%$ & $22 \%$ & $22 \%$ \\
\hline
\end{tabular}

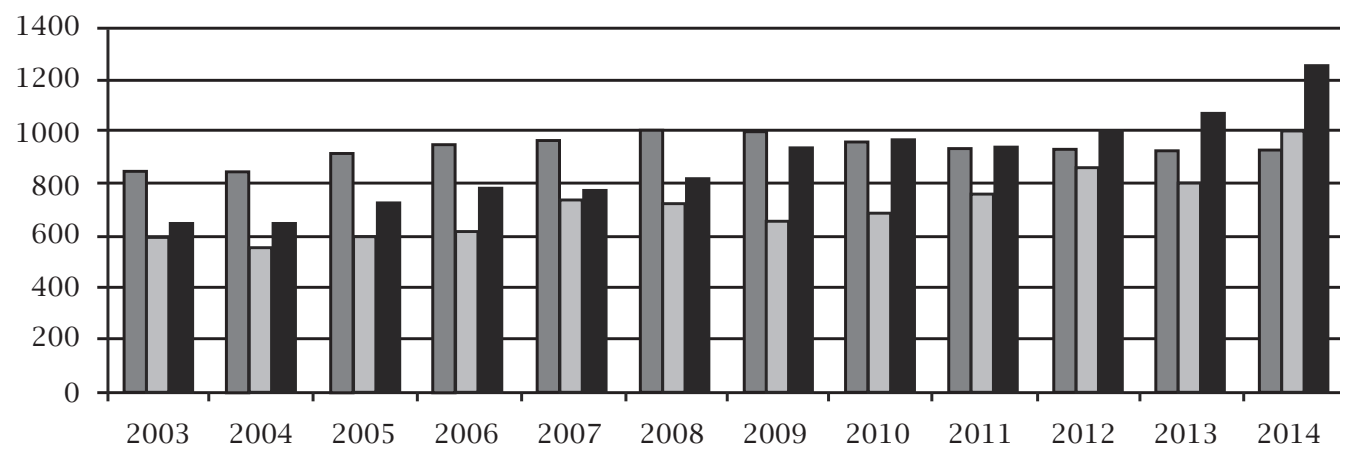

Figure 1. The former plurality of tenure-eligible faculty (mid-grey) among full-time untenured doctoral faculty in doctoral departments has been surpassed by postdocs (black) and others (silver) [1 b].

As shown in Figure 1, there are now fewer tenure-eligible faculty than postdocs or full-time doctoral faculty off the tenure track. The decline in tenure-eligible numbers cannot be explained solely by declining enrollments. The tenure-eligible faculty numbers declined with the recession of 2008 and have stagnated since. A similar pattern for tenure-eligible and full-time non-tenure-track faculty holds in departments where a Masters is the highest

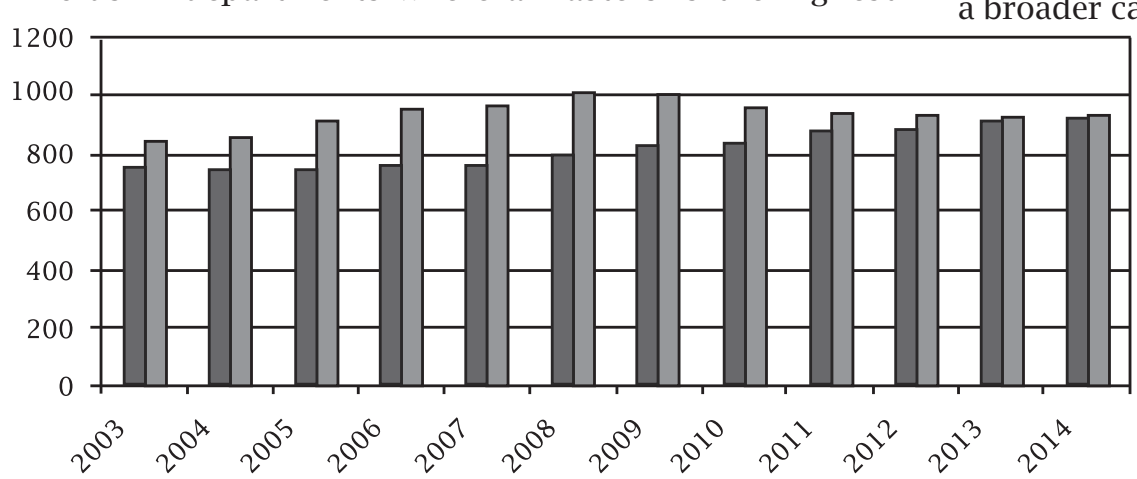

Figure 2. The ratio of tenure-eligible faculty (light grey) in doctoral institutions to thousands of undergraduate mathematics enrollments (dark grey) has been decreasing since 2009 [1 b].

degree awarded. The situation in departments that award no degree beyond a Bachelors is less stable. The number of postdocs in both Masters and Bachelors departments is small.

As shown in Figure 2, the decline in the number of tenure-eligible faculty in doctoral departments cannot be attributed to a decline in undergraduate enrollments in math courses.
Postdocs obtaining tenure-track jobs will face a range of expectations for communicating mathematics with individuals attracted by applications outside mathematics or with individuals who are not natural mathematics learners. Outside academia, they must communicate with superiors, subordinates, teams from other parts of the organization, clients, and others. People will come to them with concerns that are not clearly expressed in mathematical terms. The mathematician must clarify the problem, tease out the mathematical content, and collaborate to provide a solution that is comprehensible and applicable. Inside academia, they will see students pursuing careers (at Bachelors, Masters, or doctoral levels) outside mathematics, but requiring mathematical preparation. The great power of abstraction is not easily harnessed by nonmathematical thinkers. Mathematics faculty are expected to help students learn how to generalize from examples and how to specialize from general theory. Departments whose graduate and postdoctoral programs have goals beyond placing their students in top-tier research jobs will be able to make a broader case that they are serving the nation's need for a mathematically educated workforce.

\section{Data and Discussion Related to (2)}

Why is there such growth in hiring $\mathrm{PhD}$ mathematicians for full-time jobs off the tenure track? Many institutional pressures are active. There is increased enrollment at undergraduate levels at and beyond calculus [2]. The teaching loads of research-active mathematicians have declined. Teaching-intensive faculty are needed to meet enrollment pressure not only at entry level but beyond. Enrollment in undergraduate mathematics at sophomore through senior levels may be due to the pursuit of jobs that pay well and the fact that many well-paid jobs are in professions that require math. Deans have also noted that experienced full-time teaching-intensive faculty can generate more tuition revenue per salary dollar. A panel consisting of Sue Geller, Ellen Kirkman, and David Manderscheid [3] at the 2015 Joint Mathematics Meetings reported on the development of "career tracks" for full-time doctoral math faculty off the tenure track. 


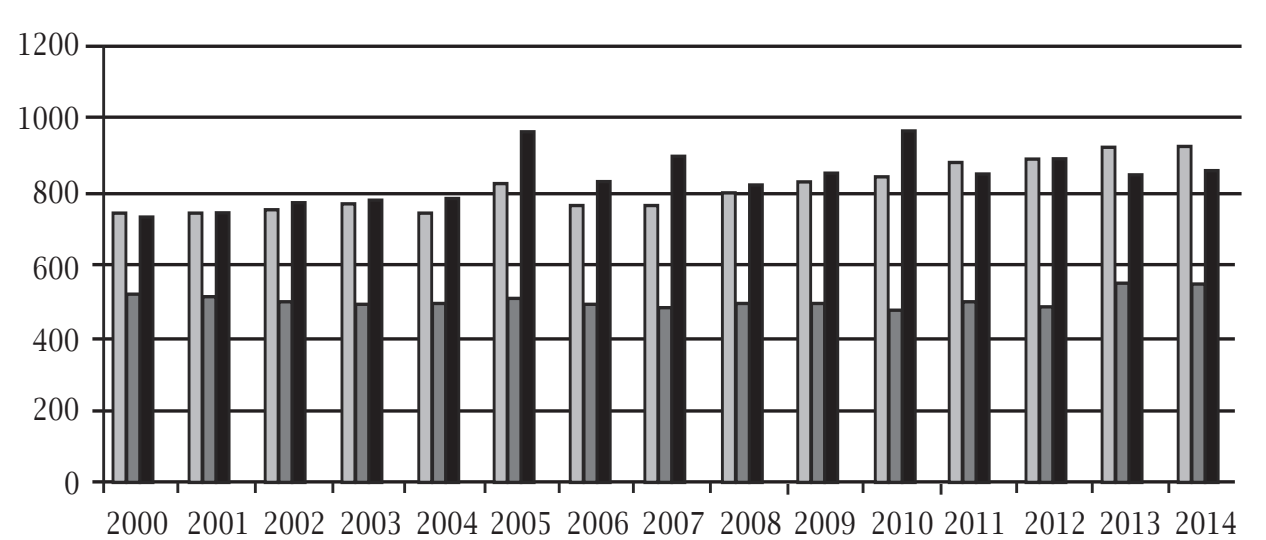

Figure 3. Undergraduate enrollments in mathematics courses, in thousands, by department type: doctoral (silver), Masters (mid-grey), and Bachelors (black) [1 b].

Ellen Kirkman serves on the Joint Data Committee and heads the CBMS surveys [2].

Over the last five years, doctoral and Masters departments accounted for just over 60 percent of total undergraduate enrollment in mathematics courses. In 2010-14 undergraduate enrollments in doctoral departments averaged 887,000 compared to 881,000 in Bachelors departments. Currently, 52 percent of tenure-eligible math faculty are at Bachelors institutions, 18 percent at Masters institutions, and 30 percent at doctoral institutions. Within doctoral institutions, 79 percent of tenure-eligible jobs are at public institutions providing broad undergraduate education. Thus, the doctoral and postdoctoral education of mathematicians whose aspirations include tenured

\section{Postdoctoral} education should not focus exclusively on research productivity academic positions should respect the teaching component as well as the scholarly component of a professorial career [1b]. Graduate students and postdocs with the greatest research potential may have the least opportunity for TA training or other explicit preparation for later teaching. Too great an early focus on research accomplishments may needlessly hinder later professional success. While institutions of higher education often have large remedial enrollments in mathematics, full-time doctoral mathematicians are generally not assigned at or below the level of precalculus [2]. Their mathematical facility may impede insight into what needs explanation and what counts as an explanation.

As noted in Table 1 , hiring of $\mathrm{PhD}$ mathematicians for full-time jobs has recently been split almost evenly between tenure-eligible positions and non-tenure-track positions. In doctoral departments, non-tenure-track hiring outnumbers tenure-eligible hiring by almost two-to-one. While postdocs are not on tenure track, data shows that non-tenure-track hiring cannot be explained solely in terms of postdocs.

As reported by Ellen Kirkman [3], all sectors of higher education increasingly employ doctoral mathematicians on "full-time non-tenuretrack career ladders." These faculty members take on roles that were formerly the primary responsibility of tenure-track faculty, for example, teaching upper-level undergraduate courses, developing or coordinating multisection courses, and mentoring undergraduate research. Thus, non-tenure-track positions have increased far beyond the traditional postdocs and adjuncts.

If non-tenure-track faculty are to continue to supply high-quality undergraduate instruction, good policies and practices are essential. The "best" graduate students may have had fellowships rather than TA experience. Postdocs carry light teaching loads and often get little mentoring for teaching. Crucial issues related to managing non-tenure-track faculty include (a) mentoring and professional development, (b) advertising vacancies, and (c) granting course reductions for scholarly activity, service, and guiding independent study or undergraduate research.

\section{Conclusions}

The health of the mathematical community requires that graduate students and early-career mathematicians see a broad range of paths to respected and satisfying careers, whether inside or outside academia. Regardless of whether we address challenge (1) or (2), postdoctoral education should not focus exclusively on research productivity [1]. The full range of professorial and nonacademic careers requires much more. The AMS should encourage departments to help postdocs prepare for (a) communicating mathematics clearly and engagingly in writing and speaking; (b) refereeing papers, reviewing for MathSciNet, writing proposals for grants, and understanding the review process; and (c) understanding nonacademic as well as academic employment opportunities.

Communicating clearly and engagingly in many venues is crucial for getting jobs and keeping them both in academic and nonacademic settings. In higher education there are seminars and conferences, teaching in classrooms, guiding independent study, directing research, and consulting. In business, industry, and government, mathematicians engage in similar activities, even if not in courses for credit toward a degree. Service to the organization and to professional societies can be expected in both career tracks. Attention to these activities will help the early-career mathematician move ahead productively and provide concrete detail for letters of recommendation. Our colleagues on the President's Council of Advisors on Science and Technology called for more explicit attention to the authentic applications of mathematics and suggested that mathematicians could be beneficially replaced 
by scientists and engineers in teaching mathematics to their majors [4].

For mathematics in the United States to flourish, we must stay attractive to students with mathematical talent and retain support from colleagues in science and engineering as well as the American public. To this end, we should enhance the educational and mentoring components of our research postdoc system and articulate responsible practices to prepare early-career doctoral mathematicians for the full range of professional opportunities and expectations both inside and outside academia. As untenured full-time doctoral mathematicians take on an increasing proportion of instruction beyond calculus, we should ensure that these colleagues can pursue their research and other scholarly interests to incorporate new mathematics and new applications into their teaching. We cannot turn back the tides of change, but we can and must cope with them constructively.

\section{Credit}

Photo of Claire Gardner, Amy Cohen, Linda Cozad, and Heather Pentifallo, courtesy of Cecilia Arias.

\section{References}

[1] www. ams.org/profession/data/annual-survey/with links noted. [1a] Hiring and Recruitment 2014; [1b] Departmental Profiles; [1c] Starting Salaries, Faculty Salaries, \& Private Communications from colleagues where categories are not broken out; [1d] New Doctoral Recipients.

[2] R. Blair, E. KIRKMAN, and J. MAXWELL, Statistical Abstract of Undergraduate Programs in the Mathematical Sciences in the US, Conference Board of the Mathematical Sciences, AMS, 2013.

[3] S. GELLER, E. KIRKMAN, and D. MANDERSCHEID, MAA-AMS Panel on Career Tracks for Full-Time Non-tenure-track Faculty. Org. by A. Cohen, D. Manderscheid, and J. Walker, JMM2015

[4] https://www.whitehouse.gov/sites/default/files/ microsites/ostp/pcast-engage-to-excel-final_feb. pdf

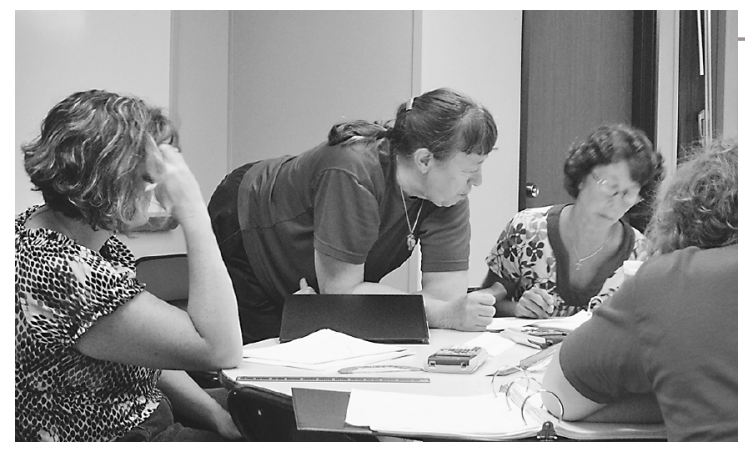

A group problem-solving session at a summer institute for middle school teachers. From left to right: Claire Gardner, Amy Cohen, Linda Cozad, Heather Pentifallo.
American Mathematical Society

\section{Let Your Voice Be Heard!}

Do you enjoy what you're reading in the Notices?

Would you like to see an article on a certain topic? Person? Situation?

Then we want to hear from you. Use our Notices Online Commentary Feature to post your general comments and suggestions:

\section{www.ams.org/notices}

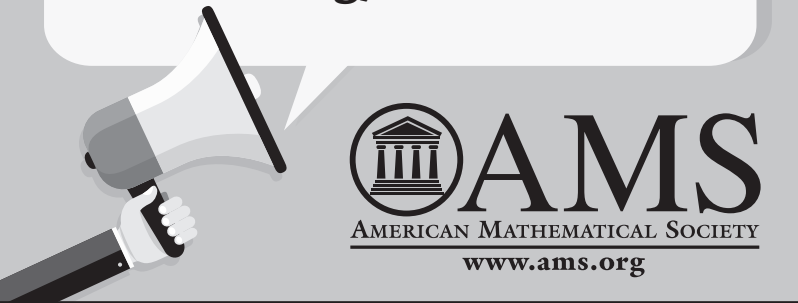

\section{ABOUT THE AUTHOR}

Amy Cohen (second from left)

Amy Cohen taught in the Berkeley public schools, at Cal State Hayward, and at Cornell before spending forty-three years on the mathematics faculty at Rutgers University before retiring as full professor. She likes people who like to learn. 